\title{
Ameliorative Effect of Mesenchymal Stromal Cells on Diabetic Nephropathy in Male Rats
}

\author{
Ahmed M. Mansour ${ }^{1}$, Hussein I. El-belbasi ${ }^{2}$, Hamad A. El-saadawy ${ }^{2}$ and Engy M.M. Yassin ${ }^{3 *}$ \\ ${ }^{1}$ Pharmacology and Toxicology Department, Faculty of Pharmacy (Boys) - Al-Azhar University, \\ Cairo, Egypt \\ ${ }^{2}$ Biochemistry Department, Faculty of Veterinary Medicine, Zagazig University, 44511, Egypt \\ ${ }^{3}$ Biochemistry Department, Faculty of Science, Zagazig University, Zagazig, Egypt
}

Article History: Received: 1/3/2017 Received in revised form: 12/4/2017 Accepted: 13/5/2017

\begin{abstract}
Both types of diabetes mellitus (DM) are recognized by the destruction of pancreas or deficient function of Islets' cells causing several complications. Diabetes mainly affect the kidney leading to diabetic nephropathy (DN) in the late renal stage, which caused higher mortality in diabetic patients. Since diabetic disease appearance, nephropathy may be observed in patients with type 1 or 2 diabetes. Recently, cell culture can be used in the regenerative medicine as a new method for treating diabetes and DN. Therefore, the aim of the current study was to prove the beneficial effect of mesenchymal stromal cells (MSCs) transplantation on DN during the early stage. Male rats were randomized in 3 groups (each 20 rats): the 1 st group was normal rats, while the $2^{\text {nd }}$ was streptozotocin (STZ) diabetic rats and the $3^{\text {rd }}$ was diabetic rats treated with a single intravenous dose of bone marrow mesenchymal stromal cells (BM-MSCs) after 3 days from STZ induction. Results indicated that STZ induced DN represented by weight loss, hyperglycemia, hypoinsulineamia, decreased glycated hemoglobin, leukocytosis and impairment of kidney function and oxidative stress in kidney tissue. After BM-MSCs treatment, blood glucose level was improved, renal function was retained, body weight loss was decreased, insulin level and HBA1C percent were ameliorated with improved oxidative stress in kidney tissue. BM-MSCs have the capacity to regenerate and differentiate into insulin- producing cells improving DM and DN.
\end{abstract}

Keywords: Diabetic Nephropathy, Streptozotocin, Oxidative Stress, Bone-Marrow mesenchymal stromal cell.

\section{Introduction}

Diabetes mellitus is followed by several complications mainly diabetic nephropathy (DN) [1], which leads to renal disease in late stage and consequently increases both morbidity and mortality in diabetic cases $[2,3]$. Oxidative stress is a major factor in diabetic vascular complications including DN $[4,5]$ as it leads to disturbance in the detoxification of reactive oxygen species (ROS) by the body which controls any damage. ROS regulates some genes and proteins that cause morphological and structural cell damage. Glycemic control may decrease the oxidative stress as it causes reduction of producing the intracellular reactive oxygen species [6]. Common therapies involve intensive control of hyperglycemia and hypertension but have no effect on diabetic nephropathy [7], so there is an important need to explore new method targeting DN.

Stem cell therapy is used as a regenerative therapy in many diseases because of its selfrenewal and differentiation properties [8,9] thus, it has the potential to be more effective than other drug therapies [10]. The most available type of these cells is mesenchymal stromal cell (MSCs), which easily obtained from human (blood, dermis, bone, bone marrow, adipose tissue and muscles) and has the ability to differentiate into other tissues as muscle, fat, cartilage and bone [11-13]. In the current study, we aimed to investigate the pancreatic and renoprotective effects of autologous transplantation of mesenchymal stromal cells derived from bone marrow (BM) in rats with streptozotocin (STZ) induced nephropathy.

\footnotetext{
*Corresponding author email: (mohamec_amin2006@yahoo.com), Biochemistry Department, Faculty of 125 Science, Zagazig University, Zagazig, Egypt.
} 


\section{Material and Methods}

\section{Experimental design}

The current study was carried out on 60 male albino rats with body weight of $200 \pm 20 \mathrm{~g}$ obtained from Standard Animal Laboratory Colony, Helwan, Cairo, Egypt. They were provided with ad libitum standard chow and water throughout the study. Rat model was performed by the Intra-peritoneal (IP) injection of $60 \mathrm{mg} / \mathrm{kg}$ STZ (Sigma-Aldrich, USA) [14] for the induction of type 1 and type 2 diabetes. After 7 days for proliferation and following one night of fasting, diabetes was confirmed by measuring fasting blood sugar of reading $>250 \mathrm{mg} / \mathrm{dL}$ for 3 continuous days. Male rats were divided into 3 groups (each 20 rats): the $1^{\text {st }}$ group was non-diabetic rats received only vehicle, while the $2^{\text {nd }}$ group was rat of type 1 diabetes that induced by $\mathrm{I} / \mathrm{P}$ injection of a single dose of STZ and not treated and the $3^{\text {rd }}$ group was diabetic rats, which received intravenous injection (I.V) of BM-MSCs in a single dose of $10^{6}$ cells/rat in 1 $\mathrm{mL}$ serum free medium (GIBCO) after 3 days from the induction of STZ.

\section{Culture, characterization and labeling of MSCs}

Bone marrow was collected and cultured for 14 days on Dulbicco's Modified Eagle's Medium (DMEM) supplemented with $10 \%$ fetal bovine serum after flushing the femurs and tibiae of 6 male rats [15]. MSCs were identified by their adhesiveness and fusiform shape. Red fluorescent cell linker (PKH26) was used in the labeling process [16] with transduction method (Sigma, Saint Louis, Missouri, USA) according to the manufacturer's recommendations.

\section{Sample collection and analysis}

Blood samples were collected for separation of serum from the retro-orbital venous sinus after 4 weeks from STZ injection for testing the biochemical parameters and blood samples for measuring hematological parameters. Kidneys were removed and divided into two parts; the first part was preserved frozen at $-80{ }^{\circ} \mathrm{C}$ for estimating the oxidative stress markers and the other part of kidney was stored in $4 \%$ formalin for histopathological examination. Also, the pancreas was stored in $4 \%$ formalin for histopathological examination and immunohistochemical analysis.

Fasting blood glucose levels were monitored along the experiment [17] while at the end of the experiment the glycosylated hemoglobin [18], insulin [19], creatinine [20] and urea [21] were estimated. On the day 27 after MSCs injection (1 month from diabetes induction) and adaptation at early phase of diabetic nephropathy induced by STZ, rats were scarified and pancreas and kidney were removed for preparing paraffin block then stained by hematoxylin-eosin for histopathologic analysis under light microscope. PKH26 labeled MSCs were examined under fluorescence microscope [22].

An immunohistochemical staining on $4 \mu \mathrm{m}$ frozen pancreatic sections was performed according to the streptavidin biotin peroxidase complex (ABC) method using primary Antiinsulin antibody (guinea pig polyclonal to insulin, ab7842, Abcam, Cambridge, UK) and rabbit polyclonal secondary antibody (Rabbit polyclonal secondary antibody to guinea pig IgG - H\&L Horse Radish Peroxidase (HRP), ab6771, Abcam, Cambridge, UK) on unstained positively charged slides from paraffin block [23]. Morphometric analysis was performed to measure the nuclear area and length of $\beta$ cells of islet of pancreases using National Institute of Health (NIH) technique 1.60 programs (NIH, Bethesda, Maryland, USA) [24]. The results were represented the effectiveness of the newly produced $\beta$-cells of pancreases. The malondialdehyde (MDA) content (thiobarbituric acid method [25]), the total superoxide dismutase (SOD) activity (xanthine oxidase method [26]) and reduced glutathione content of kidney homogenate (Ellman's method [27]) were measured with commercially available kits (Biodiagnostic Co. Cairo Egypt)

\section{Statistical analysis}

All data were represented by mean \pm SE using Prism version 7 program. One-way ANOVA analysis was used to compare the different experimental groups. 
Table 1: Effect of BM-MSCs on body weight, fasting blood sugar (FBS), glycated hemoglobin (HBA1C) and insulin in induced-diabetic rats (Mean $\pm \mathrm{SE}, \mathrm{N}=20)$

\begin{tabular}{lccc}
\hline Group variables & Control group & DN group & BM-MSCs group $^{2}$ \\
\hline Body weight $(\mathbf{g})$ & $303.3 \pm 8.5^{\mathrm{a}}$ & $226.73 \pm 6.93^{\mathrm{b}}$ & $300.50 \pm 12.57^{\mathrm{a}}$ \\
FBS $(\mathbf{m g} / \mathbf{d L})$ & $96.50 \pm 2.63^{\mathrm{c}}$ & $269 \pm 28.01^{\mathrm{a}}$ & $175.62 \pm 7.11^{\mathrm{b}}$ \\
HbA1C $(\%)$ & $5.46 \pm 0.30^{\mathrm{c}}$ & $12.22 \pm 0.23^{\mathrm{a}}$ & $8.52 \pm 0.33^{\mathrm{b}}$ \\
Insulin $(\boldsymbol{\mu} / \mathbf{g})$ & $0.75 \pm 0.04^{\mathrm{a}}$ & $0.2 \pm 0.021^{\mathrm{c}}$ & $0.54 \pm 0.04^{\mathrm{b}}$ \\
\hline
\end{tabular}

${ }^{1} \mathrm{DN}$ group: rats of type 1 diabetes that induced by I/P injection of a single dose of STZ and not treated, ${ }^{2} \mathrm{BM}-\mathrm{MSCs}$ group: diabetic rats, which received intravenously injection of BM-MSCs in a single dose of $10^{6} \mathrm{cells} / \mathrm{rat}$ in $1 \mathrm{~mL}$ serum free medium (GIBCO) after 3 days from the induction of STZ. Means carrying different superscript within the same row were significant different at $p<0.05$.

\section{Results and Discussion}

Four weeks after STZ injection, rats in the DN group showed light body weight and high blood sugar $(\mathrm{P}<0.05)$ when compared with the non-diabetic group, while rats of the BMMSCs treated group revealed heavy body weight and low blood sugar $(\mathrm{P}<0.05)$ when compared with the DN group (Table 1). Glycated hemoglobin showed a higher increase $(\mathrm{P}<0.05)$ in the $\mathrm{DN}$ group when compared with the non-diabetic group, however it was significantly lower in the BM-
MSCs group when compared with the DN group. Moreover, insulin was significantly decreased in the DN group when compared with the control one, while, it showed ameliorative effect in the treated group compared with DN group (Table 1). The serum urea and creatinine levels in the DN rats were higher than the non-diabetic rats and their levels were significantly reduced after the injection of BM-MSCs when compared with DN group (Table 2).

Table 2: Effect of BM-MSCs on renal functions and oxidative stress markers in the renal tissue of induceddiabetic rats (Mean \pm SE, $N=20$ )

\begin{tabular}{lccc}
\hline Group variables & Control group & DN group $^{1}$ & BM-MSCs group $^{2}$ \\
\hline Urea (mg/dL) & $45.57 \pm 2.48^{\mathrm{c}}$ & $93.48 \pm 7.19^{\mathrm{a}}$ & $62.67 \pm 2.17^{\mathrm{b}}$ \\
Creatinine (mg/dL) & $0.58 \pm 0.017^{\mathrm{c}}$ & $2.78 \pm 0.22^{\mathrm{a}}$ & $1.60 \pm 0.15^{\mathrm{b}}$ \\
${ }^{\mathbf{3}} \mathrm{SOD}(\mathbf{U} / \mathbf{g})$ & $195.5 \pm 12.67^{\mathrm{a}}$ & $105.67 \pm 4.62^{\mathrm{c}}$ & $171.72 \pm 11.6^{\mathrm{b}}$ \\
${ }^{\mathbf{4}} \mathbf{M D A}(\mathbf{n m o l} / \mathbf{m g})$ & $1.78 \pm 0.28^{\mathrm{c}}$ & $4.98 \pm 0.22^{\mathrm{a}}$ & $3.2 \pm 0.22^{\mathrm{b}}$ \\
${ }^{\mathbf{5}} \mathbf{G S H}(\mathbf{U} / \mathbf{g})$ & $33.03 \pm 2.97^{\mathrm{a}}$ & $22.51 \pm 0.55^{\mathrm{b}}$ & $25.15 \pm 0.65^{\mathrm{b}}$
\end{tabular}

${ }^{\mathrm{DN}}$ group: rats of type 1 diabetes that induced by I/P injection of a single dose of STZ and not treated, ${ }^{2} \mathrm{BM}-\mathrm{MSCs}$ group: diabetic rats, which received I.V injection of BM-MSCs in a single dose of $10^{6}$ cells/rat in $1 \mathrm{~mL}$ serum free medium (GIBCO) after 3 days from the induction of STZ. ${ }^{3}$ SOD: superoxide dismutase activity; ${ }^{4}$ MDA: malondialdehyde content; ${ }^{5} \mathrm{GSH}$ : reduced glutathione content. Means carrying different superscript within the same row were significant different at $\mathrm{p}<0.05$.

Our results suggested that, BM-MSCs was able to control the alteration of the oxidative stress in the kidney homogenate of diabetic rats where the treated group exhibited a significant increase $(\mathrm{P}<0.05)$ in the SOD activity and the GSH concentrations when compared with the DN group. In addition, the MDA concentration showed a significant decrease $(\mathrm{P}<0.05)$ in the BM-MSCs treated group when compared with DN group (Table 2 ). These results were confirmed with the improvement in the histological examination of pancreas and kidney after BM-MSCs treatment (Figure 1). As a result of immunohistochemical (IHC) examination, there was small islets regeneration in the BMMSCs treated group (Figure 2) confirmed by the improvement in insulin levels and blood glucose levels, which indicated the beneficial role of MSCs in amelioration of DN. The islets regeneration indicated also by morphometric analysis showed that the nuclear size and length of islet cell increased significantly after BM-MSCs transplantation when compared with the DN group (Table 3). 
Table 3: Some nuclear morphometric features (Nuclear area and length) in different groups $(\mathrm{Mean} \pm \mathrm{SE}, \mathrm{N}=$ 20)

\begin{tabular}{lccc}
\hline Morphometric feature & Control group & DN group $^{1}$ & BM-MSCs group $^{2}$ \\
\hline Nuclear area $(\boldsymbol{\mu m} 2)$ & $11.57 \pm 3.61^{\mathrm{a}}$ & $6.42 \pm 2.71^{\mathrm{c}}$ & $10.29 \pm 4.41^{\mathrm{b}}$ \\
Nuclear length $(\boldsymbol{\mu m})$ & $13.43 \pm 2.10^{\mathrm{a}}$ & $9.66 \pm 0.2 .29^{\mathrm{c}}$ & $12.25 \pm 2.85^{\mathrm{b}}$
\end{tabular}

${ }^{1} \mathrm{DN}$ group: rats of type 1 diabetes that induced by I/P injection of a single dose of STZ and not treated, ${ }^{2} \mathrm{BM}-\mathrm{MSCs}$ group: diabetic rats, which received intravenously injection of BM-MSCs in a single dose of $10^{6}$ cells $/ \mathrm{rat}$ in $1 \mathrm{~mL}$ serum free medium (GIBCO) after 3 days from the induction of STZ. Means carrying different superscript within the same row were significant different at $\mathrm{p}<0.05$.

Supporting to our results, blood sugar was reduced by a single injection of MSCs in STZ- induced diabetic rats [28,29]. Also, the intravenous injection of adipose-derived mesenchymal stem cells (ADMSC) in diabetic mice could significantly decrease the fasting blood sugar level and increase the secretion of insulin in the islet $\beta$-cells [30]. A previous study was performed by Tsai et al. [31] who found that mesenchymal stem cells (MSCs) derived from the human bone marrow were differentiated into new pancreatic cells alleviated the increase in blood glucose in diabetic group. On similar ground, a streptozotocin (STZ) diabetic rat model treated with MSC injection at the early ( 7 days) and late phase ( 21 days) could be able to control the hyperglycemia in diabetic rats with type 2 [32]. Zhang, et al. [33] reported that the increased blood glucose was associated with the decreased insulin secretion in the diabetic rats when compared with the non-diabetic rats and it was improved after treated with MSCs, which represented by tubular dilatation, mesangial expansion and glomerular sclerosis observed histopathologically under light microscope. Similar to our result, Lee et al. [34] and Ezquer et al. [35] showed that hyperglycemia and renal histology of diabetic rat was improved by MSC therapy when compared with the DN group. Lang and Dai [36] study showed that, there was an increase in the mesangial cells and mesangial matrix in diabetic rats when compared with the non-diabetic rats whereas in the MSC group, the histopathological changes were improved inhibiting the renal fibrosis compared with the DN group. 

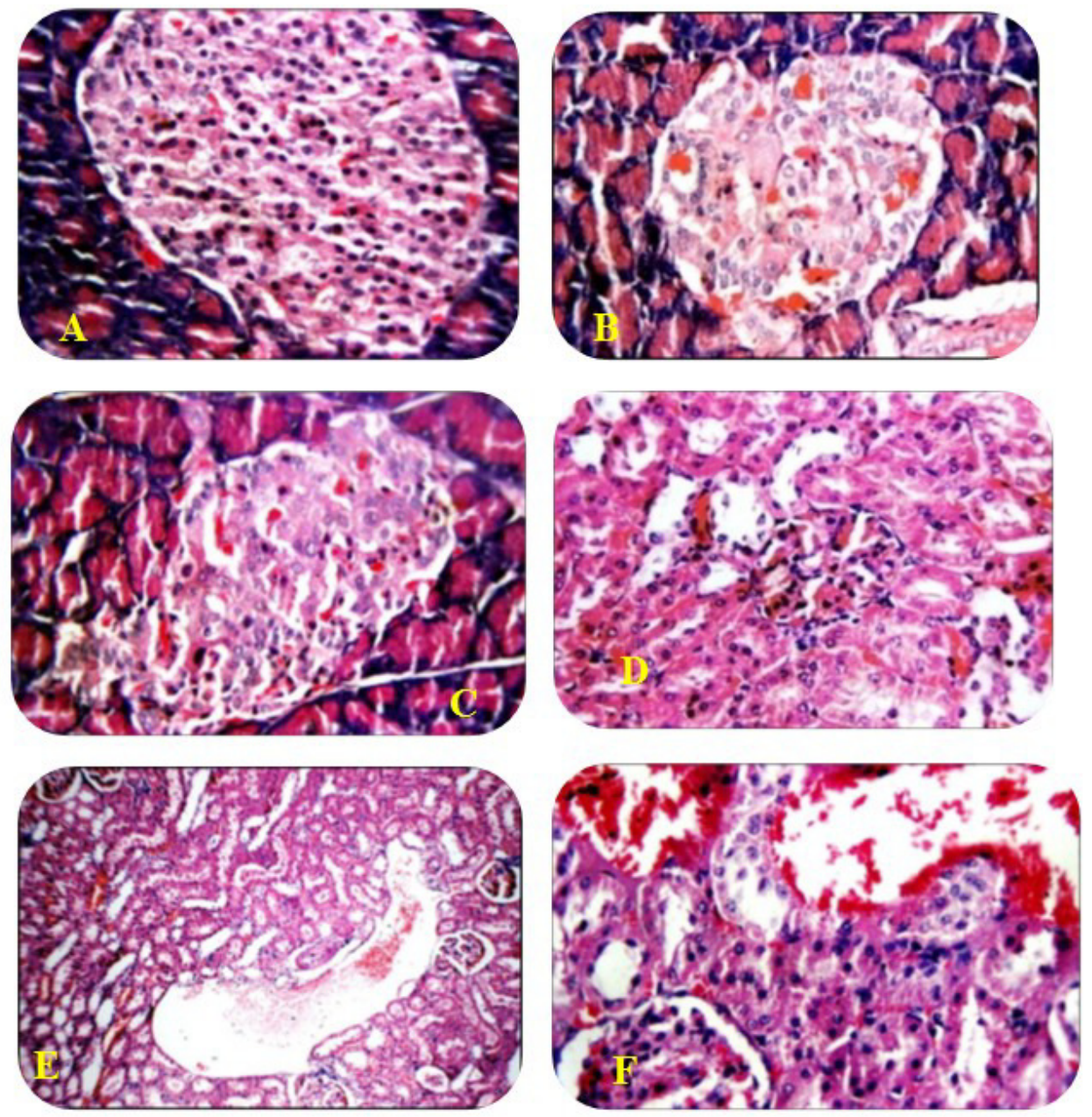

Figure 1: A- Normal pancreatic section from the control group (H\&E X 360), B- The DN group showed necrotic Islets' cells of pancreas and marked edema (H\&E X360), C- The BM-MSCs treated group showed more cellular Islets of pancreas (H\&E X 360), D- Normal kidney section from the control group (H \& E X 360), E- The DN group showed markedly dilated congested blood vessel in the kidney (H \& E X 360), F- The BM-MSCs treated group showed average glomerulus and tubules in the kidney (H \& E X 360).
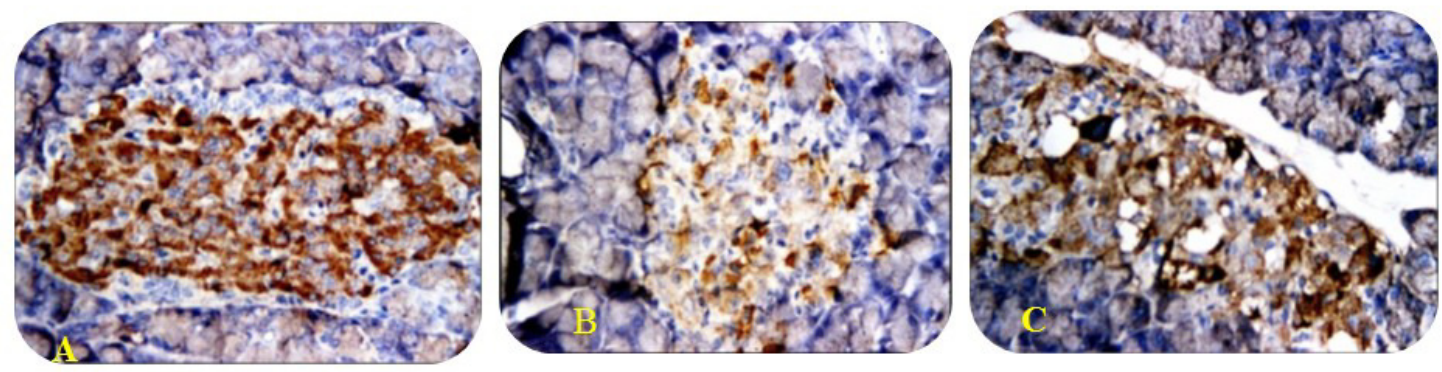

Figure 2: A- Normal pancreatic section from the control group showed marked cytoplasmic reactivity to insulin antibodies (insulin immunostain $x$ 360). B- The DN group showed mild cytoplasmic reactivity to insulin antibodies (insulin immunostain $x$ 360). C- The BM-MSCs treated group showed marked reactivity to insulin antibodies (insulin immunostain $x$ 360). 
Serum urea and creatinine were lowered after the BM-MSCs treatment due to the decrease protein degradation and the increase of their clearance by the kidney [37]. In contrary with our study, compared with the DN group, the single transplantation of MSCs didn't affect blood glucose levels in diabetic rats, whereas repeated injection for 7 days could significantly control it [38]. Moreover, a study of Ezquer et al. [39] demonstrated that, administration of MSCs in a mouse model did not result in hyperglycemia correction. In addition, Wang et al. [12] provided clear evidence that the injected MSCs prevented the development of albuminuria and loss of podocytes but there was no improvement in blood sugar levels. MSCs was used to ameliorate hyperglycemia, suppress oxidative stress in kidney homogenate and improve renal histopathological changes in diabetic rats with DN [40]. Liu et al. [41] reported that the IHC of the DN group showed mild cytoplasmic reactivity to insulin antibodies when compared with the control group and after treated with BM-MSCs, the pancreatic tissue showed marked reactivity to insulin antibodies (more than $75 \%$ of Islets' cells) when compared with the DN group, which supported our findings.

\section{Conclusion}

Bone marrow mesenchymal stromal cells had the ability to renew into islet cells and were differentiated into functional insulin secreting cells, which indicated its beneficial effects on diabetes-induced nephropathy and strongly recommended BM-MSCs in treating clinical cases of DM and DN as a future therapy.

\section{Conflict of interest}

The authors declare no conflict of interest.

\section{References}

[1] Collins, A.J.; Foley, R.N.; Herzog, C.; Chavers, B.; Gilbertson, D. Herzog, C.; Ishani, A.; Johansen, K.; Kasiske, B.; Kutner, N. and Liu, J. (2013): US Renal Data System 2012 Annual Data Report. Am J Kidney Dis, 61(7): E1-E459.

[2] Collins, A.J.; Foley, R.N.; Gilbertson, D.T. and Chen, S.C. (2009): The state of chronic kidney disease, ESRD, and morbidity and mortality in the first year of dialysis. Clin J Am Soc Nephrol, 4(Suppl 1):5-11.

[3] Mariappan, M.M. (2012): Signaling mechanisms in the regulation of renal matrix metabolism in diabetes. Exp Diabetes Res, Volume 2012, Article ID 749812, $\quad 10 \quad$ pages. doi:10.1155/2012/749812

[4] Giacco, F. and Brownlee, M. (2010): Oxidative stress and diabetic complications. Circ Res, 107(9):10581070.

[5] Yamagishi, S.I.; Maeda, S.; Matsui, T.; Ueda, S.; Fukami, K. and Okuda, S. (2012): Role of advanced glycation end products (AGEs) and oxidative stress in vascular complications in diabetes. Biochim Biophys Acta (BBA)-General Subjects, 1820(5):663-671.

[6] Ha, H. and Lee, H.B. (2005): Reactive oxygen species amplify glucose signalling in renal cells cultured under high glucose and in diabetic kidney. Nephrol, 10(S2):S7-S10.

[7] Xu, L.; Shen, P.; Bi, Y. ; Chen, J.; Xiao, Z.; Zhang, X. and Wang, Z. (2016): Danshen injection ameliorates STZinduced diabetic nephropathy in association with suppression of oxidative stress, pro-inflammatory, factors and fibrosis. Int Immunopharmacol, 38:385394.

[8] Morigi, M.; Introna, M.; Imberti, B.; Corna, D.; Abbate, M.; Rota, C.; Rottoli, D.; Benigni, A.; Perico, N.; Zoja, C. and Rambaldi, A. (2008): Human bone marrow mesenchymal stem cells accelerate recovery of acute renal injury and prolong survival in mice. Stem Cells, 26(8):2075-2082.

[9] Semedo, P.; Correa-Costa, M.; Antonio Cenedeze, M.; Maria Avancini Costa Malheiros, D.; Antonia dos Reis, M.; Shimizu, M.H.; Seguro, A.C.; Pacheco Silva, A.; Camara, S. and Olsen, N. (2009): Mesenchymal stem cells attenuate renal fibrosis through immune modulation and remodeling properties in a rat remnant kidney model. Stem Cells, 27(12):3063-3073. 
[10] Tögel, F. and Westenfelder, C. (2007): Adult bone marrow-derived stem cells for organ regeneration and repair. Dev Dyn , 236(12):3321- 3331.

[11] Ezquer, F.; Ezquer, M.; Simon, V.; Pardo, F.; Yañez, A.; Carpio, D. and Conget, P. (2009): Endovenous administration of bone-marrow-derived multipotent mesenchymal stromal cells prevents renal failure in diabetic mice. Biol Blood Marrow Transplant, 15(11):1354-1365.

[12] Wang, S.; Li, Y.; Zhao, J.; Zhang, J. and Huang, Y. (2013): Mesenchymal stem cells ameliorate podocyte injury and proteinuria in a type 1 diabetic nephropathy rat model. Biol Blood Marrow Transplant, 19(4):538-546.

[13] Ho, J.H.; Tseng, T.C.; Ma, W.H.; Ong, W.K.; Chen, Y.F.; Chen, M.H.; Lin, M.W.; Hong, C.Y. and Lee, O.K. (2012): Multiple intravenous transplantations of mesenchymal stem cells effectively restore long-term blood glucose homeostasis by hepatic engraftment and cell differentiation in streptozocininduced diabetic mice. Cell Transpl, 21(5):997-1009.

[14] Abdel Aziz, M. T.; Wassef, M.A.; Ahmed, H.H.; Rashed, L.; Mahfouz, S.; Aly, M.I.; Hussein, R.E. and Abdel Aziz, M. (2014): The role of bone marrow derived-mesenchymal stem cells in attenuation of kidney function in rats with diabetic nephropathy. Diabetol Metab Syndr, 6(1):1-34.

[15] Lv, S.S.; Liu, G.; Wang, J.P.; Wang, W.W.; Cheng, J.; Sun, A.L.; Liu, H.Y., Nie, H.B.; Su, M.R. and Guan, G.J. (2013): Mesenchymal stem cells transplantation ameliorates glomerular injury in streptozotocin-induced diabetic nephropathy in rats via inhibiting macrophage infiltration. Int Immunopharmacol, 17(2):275-282.

[16] Wallace, P.K.; Tario, J.D.; Fisher, J.L.; Wallace, S.S.; Ernstoff, M.S. and Muirhead KA. (2008): Tracking antigendriven responses by flow cytometry: monitoring proliferation by dye dilution. Cytometry A, 73(11): 1019-1034.
[17] Trinder, P. (1969): Determination of glucose in blood using glucoseboxidase with an alternative oxygen acceptor. Annals Clin Biochem, 6(1):24-27.

[18] Sudhakar, N.S. and Pattabiraman, T.N. (1981): A new colorimetric method for the estimation of glycosylated haemoglobin. Clin Chimica Acta, 109: 267-274.

[19] Zisman, A.; Peroni, O.D.; Abel, E.D.; Michael, M.D.; Mauvais-Jarvis, F.; Lowell, B.B.; Wojtaszewski, J.F.; Hirshman, M.F.; Virkamaki, A.; Goodyear, L.J. and Kahn, C.R. (2000): Targeted disruption of the glucose transporter 4 selectively in muscle causes insulin resistance and glucose intolerance. Nat Med, 6(8):924-928.

[20] Husdan, H. and Rapoport, A. (1968): Estimation of creatinine by the Jaffe Reaction. Clin Chem. 14(3):222-238.

[21] Marsh, H.W.; Fingerhut, B. and Miller, H. (1965): Automated and manual direct methods for the determination of blood urea. Clin Chem, 11(6):624-627.

[22] Sordi, V.; Melzi, R.; Mercalli, A.; Formicola, R.; Doglioni, C.; Tiboni, F.; Ferrari, G.; Nano, R.; Chwalek, K.; Lammert, E. and Bonifacio, E. (2010): Mesenchymal cells appearing in pancreatic tissue culture are bone marrow-derived stem cells with the capacity to improve transplanted islet function. Stem Cells, 28(1):140-151.

[23] Aali, E.; Mirzamohammadi, S.; Ghaznavi, H.; Madjd, Z.; Larijani, B.; Rayegan, S.; and Sharifi, A.M. (2014). A comparative study of mesenchymal stem cell transplantation with its paracrine effect on control of hyperglycemia in type 1 diabetic rats. J Diabetes Metab Disord, 13, 76. http://doi.org/10.1186/22516581-13-76

[24] Kitamura, T.; Kido, Y.; Nef, S.; Merenmies, J.; Parada, L.F. and Accili, D. (2001): Preserved pancreatic beta-cell development and function in mice lacking the insulin receptor-related receptor. Mol Cell Biol, 21(16):56245630. 
[25] Uchiyama, M. and Mihara, M. (1978): Determination of malonaldehyde precursor in tissues by thiobarbituric acid test. Anal Biochem, 86(1):271-278.

[26] Marklund, S.L. (1985): Superoxide dismutase isoenzymes in tissues and plasma from New Zealand black mice, nude mice and normal BALB/C mice. Mutat Res, 148 (1):129-134.

[27] Ellman, G.L. (1959): Tissue sulfhydryl groups. Arch Biochem Biophys, 82(1):70-77.

[28] Abdi, R.; Fiorina, P.; Adra, C.N.; Atkinson, M. and Sayegh, M.H. (2008): Immunomodulation by mesenchymal stem cells: A potential therapeutic strategy for type 1 diabetes. Diabetes, 57(7):1759-1767.

[29] Chen, L.; Gao, G.Q.; Wang, L.; Song, J.; Chen, B.; Xu, Y.X. and Sun, L. (2008): Allogeneic diabetic mesenchymal stem cells transplantation in streptozotocininduced diabetic rat. Clin Invest Med, 31(6):328-337.

[30] Li, Y.Y.; Liu, H.H.; Chen, H.L. and Li, Y.P. (2012): Adipose-derived mesenchymal stem cells ameliorate STZinduced pancreas damage in type 1 diabetes. Biomed Mater Eng, 22(1-3):97103.

[31] Tsai, P.J.; Wang, H.S.; Lin, C.H.; Weng, Z.C.; Chen, T.H. and Shyu, J.F. (2014): Intraportal injection of insulin-producing cells generated from human bone marrow mesenchymal stem cells decreases blood glucose level in diabetic rats. Endocr Res, 39(1):26-33.

[32] Si, Y.; Zhao,Y.; Hao, H.; Liu, J.; Guo, Y.; $\mathrm{Mu}$, Y.; Shen, J.; Cheng, Y.; Fu, X. and Han, W. (2012): Infusion of Mesenchymal Stem Cells Ameliorates Hyperglycemia in Type 2 Diabetic Rats Identification of a Novel Role in Improving Insulin Sensitivity .Diabetes, 61(6): 1616-1625

[33] Zhang, Y.; Ye, C.; Wang, G.; Gao, Y.; Tan, K.; Zhuo, Z.; Liu, Z.; Xia, H.; Yang, D. and Li, P. (2013): KidneyTargeted Transplantation of Mesenchymal Stem Cells by Ultrasound-
Targeted Microbubble Destruction Promotes Kidney Repair in Diabetic Nephropathy Rats. Bio. Med. Research Int, Volume 2013, Article ID 526367, 13 pages http://dx.doi.org/10.1155/2013/526367

[34] Lee, R.H.; Seo, M.J.; Reger, R.L.; Spees, J.L., Pulin, A.A., Olson, S.D. and Prockop, D.J. (2006): Multipotent stromal cells from human marrow home to and promote repair of pancreatic islets and renal glomeruli in diabetic NOD/scid mice. Proc Natl Acad Sci U S A, 103(46):17438-17443

[35] Ezquer, F.E.; Ezquer, M.E.; Parrau, D.B.; Carpio, D.; Yañez, A.J. and Conget, P.A. (2008): Systemic administration of multipotent mesenchymal stromal cells reverts hyperglycemia and prevents nephropathy in type 1 diabetic mice. Biol Blood Marrow Transplant,14(6):631640.

[36] Lang, H. and Dai, C. (2016): Effects of Bone Marrow Mesenchymal Stem Cells on Plasminogen Activator Inhibitor-1 and Renal Fibrosis in Rats with Diabetic Nephropathy. Arch Med Res, 47(2):7177.

[37] Raish, M.; Ahmad, A.; Jan, B.L.; Alkharfy, K.M.; Ansari, M.A.; Mohsin, K.; Jenoobi, F. and Al-Mohizea, A. (2016): Momordica charantia polysaccharides mitigate the progression of STZ induced diabetic nephropathy in rats. Int J Biol Macromol, 91(1):394-399.

[38] Fawzy, M.S.; Gharib, A.F.; Shalaby, S.M.; Abdel-nour H.M. and Alnahal, A. (2016): The role of stem cell injection in amelioration of diabetic nephropathy in experimentally induced diabetic rats. Int J Adv Res, 4(10):1412-1419.

[39] Ezquer, F.; Ezquer, M.; Contador, D.; Ricca, M.; Simon, V. and Conget, P. (2012): The antidiabetic effect of mesenchymal stem cells is unrelated to their trans-differentiation potential but to their capability to restore th1/th2 balance and to modify the pancreatic microenvironment. Stem cells, 30(8):1664-1674. 
[40] Lv, S.; Cheng, J.; Sun, A.; Li, J.; Wang, W.; Guan, G.; Liu G. and Su, M. (2014): Mesenchymal stem cells transplantation ameliorates glomerular injury in streptozotocin-induced diabetic nephropathy in rats via inhibiting oxidative stress. Diabetes Res Clin Pract, 104(1):143-154.
[41] Liu, X.; Zheng, P.; Wang, X.; Dai, G.; Cheng, H; Zhang, Z.; Hua, R.; Niu, X.; Shi, J. and An, Y. (2014): A preliminary evaluation of efficacy and safety of Wharton's jelly mesenchymal stem cell transplantation in patients with type 2 diabetes mellitus. Stem Cell Res Ther, $5(2): 1-57$.

$$
\begin{aligned}
& \text { التأثير المحسن للخلايا الجذعية الوسيطه علي اعتلال العبي الكلي السكري في ذكور الجرذان }
\end{aligned}
$$

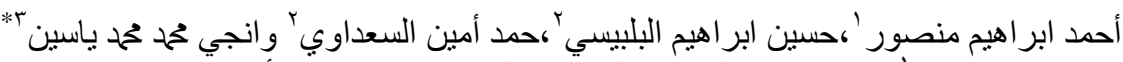

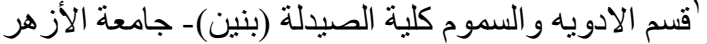

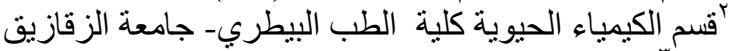

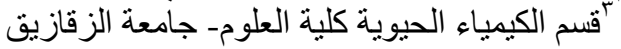

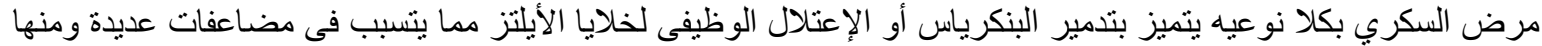

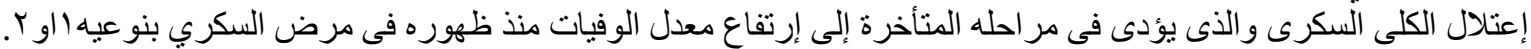

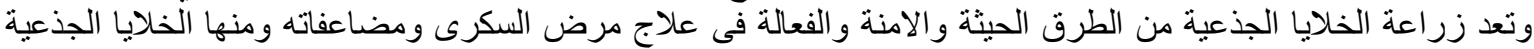

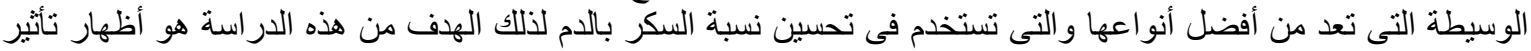

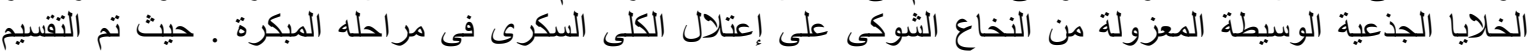

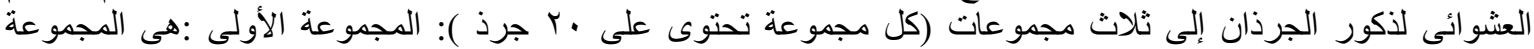

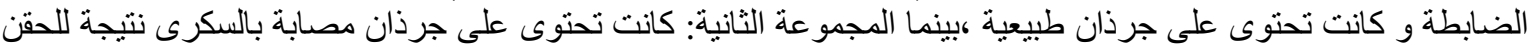

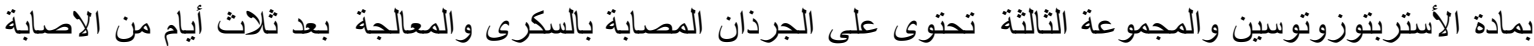

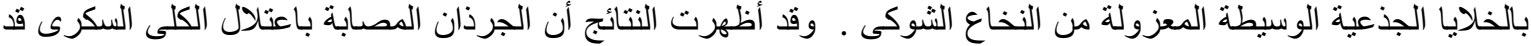

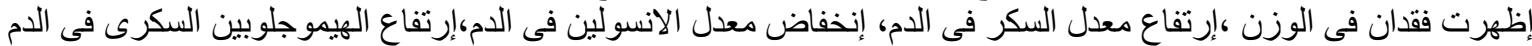

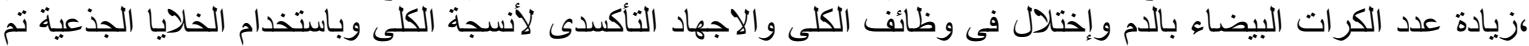

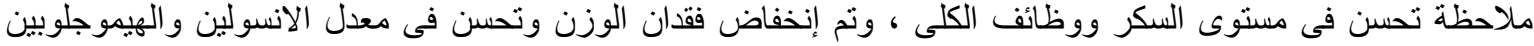

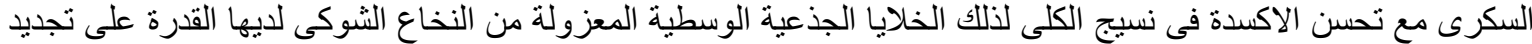

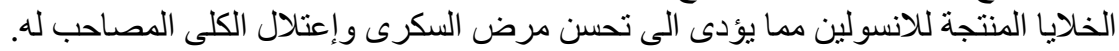

